\title{
Maturation and regulation of the motility of spermatozoa in the epididymis of the tammar wallaby (Macropus eugenii)
}

\author{
J. Clulow, R. C. Jones and R. N. Murdoch \\ Department of Biological Sciences, University of Newcastle, NSW, Australia 2308
}

\begin{abstract}
Summary. Demembranated spermatozoa from the rete testis developed vigorous flagellation when reactivated with ATP, but showed no forward progression such as that seen in samples from the cauda epididymidis. The proportion of spermatozoa that were reactivated was smaller for samples from the rete testis than from the cauda epididymidis.

Studies in vitro of undiluted micropuncture samples from the epididymis indicated that the activity of spermatozoa is suppressed as they develop the capacity for motility. However, as spermatozoa spontaneously became activated during the collection or subsequent incubation of undiluted samples, it was concluded that the suppressive action is labile.

The activity of spermatozoa in vitro was examined in diluted samples from the cauda epididymidis. A concentration of $2.5 \mathrm{mmol}$ extracellular calcium/1 was better than lower concentrations. Diluents at $\mathrm{pH} 5.5$ completely inhibited sperm motility when they contained $20 \mathrm{mmol}$ lactate/l (but not glutamate) and the effect was reversed by readjusting the diluent to $\mathrm{pH} 7 \cdot 4$. However, lactate was not considered to suppress sperm motility in situ, as the plasma from the cauda epididymidis contained only $2.7 \pm 0.5 \mathrm{mmol}$ lactate $/ \mathrm{l}$. There was no effect of sodium concentration (1 and $115 \mathrm{mmol} / \mathrm{l})$, pH $(5.5$ and 7.4$)$ or amiloride $(0$ and $1 \mathrm{mmol} / 1)$ on sperm motility, indicating that motility is not dependent on the concentration of sodium above $1 \mathrm{mmol} / \mathrm{l}$ or on a sodium-proton exchange system.

The relative viscosity of plasma from the cauda epididymidis did not affect the motility of spermatozoa.
\end{abstract}

Kelwords: sperm maturation; sperm activation; sperm motility; marsupial spermatozoa; tammar wallaby

\section{Introduction}

Mammalian spermatozoa acquire the capacity for motility during epididymal transit. However, studies of reactivated, demembranated spermatozoa from hamsters (Mohri \& Yanagamachi, 1980), rats (Yeung, 1984) and bulls (White \& Voglmayr, 1986) showed that testicular spermatozoa have the capacity for the same pattern of motility as spermatozoa from the cauda epididymidis, indicating that this aspect of sperm development may involve only changes to the plasma membrane. As the epididymal maturation of marsupial spermatozoa involves more extensive modifications to the tail than that of eutherian spermatozoa (Harding et al., 1975, 1979), we compared the effect of reactivating demembranated spermatozoa from the rete testis and cauda epididymidis of the tammar.

There is considerable variation in reports of the initial activity of spermatozoa collected from the cauda epididymidis of prototherian and eutherian mammals. For example, it has been concluded 
that spermatozoa are immotile in samples from rats, hamsters, guinea-pigs and elephants (R. C. Jones, 1973, 1978; Morton et al., 1978; Carr et al., 1985; Turner \& Reich, 1985) and highly motile in samples from rabbit, ram, rhesus monkey and echidna (R. Jones, 1978; Morton et al., 1978; Djakiew \& Jones, 1983; Usselman \& Cone, 1983; Turner \& Reich, 1985). Weak motility has been described in samples from dogs (Carr et al., 1985), whilst samples from bulls are reported to have moderate to strong motility (Morton et al., 1978; Pholpramool et al., 1985) or low motility (Cascieri et al., 1976; Carr \& Acott, 1984; Carr et al., 1985). This report shows that sperm motility is suppressed during transit through the epididymis of tammars and that the suppression is labile.

As there are no reports on the regulation of motility of marsupial spermatozoa in situ (Jones, 1989), the factors that have been implicated in regulating the activity of eutherian spermatozoa were studied in tammars. These factors include extracellular sodium (Lee et al., 1981; Wong et al., 1981; Wong \& Lee, 1985), intracellular pH (Babcock et al., 1983; Acott \& Carr, 1984; Carr \& Acott, 1984, 1989; Carr et al., 1985; Vijayaraghavan et al., 1985; Lindemann \& Kanous, 1989), and the viscosity (Usselman \& Cone, 1983; Carr et al., 1985), lactate concentration (Acott \& Carr, 1984; Carr et al., 1985; Turner \& Reich, 1985; Carr \& Acott, 1989) and calcium concentration (Morton et al., 1978; Garbers \& Kopf, 1980; Lee et al., 1981; Tash \& Means, 1983; Lindemann \& Kanous, 1989) of the extracellular fluid.

\section{Materials and Methods}

The source of the animals and the micropuncture procedures were reported previously (Jones, 1987). Spermatozoa were collected from the rete testis, the distal caput epididymidis, the mid-corpus epididymidis and the distal cauda epididymidis corresponding to regions 8,13 and 22, respectively, described by Jones et al. (1984).

\section{Reactivation of demembranated spermatozoa}

The method described by White \& Voglmayr (1986) was used. It involved washing micropuncture samples twice in calcium-free Krebs-Ringer phosphate, centrifugation for $10 \mathrm{~min}$ at $200 \mathrm{~g}$ and resuspension in extraction buffer (containing $0.1 \% \mathrm{v} / \mathrm{v}$ Triton $\mathrm{X}-100$ and $50 \mu \mathrm{mol} \mathrm{cAMP} / \mathrm{l})$ at a final concentration of $5.0 \times 10^{5}$ spermatozoa $/ \mathrm{ml}$ for samples from the rete testis, or $1.2 \times 10^{6}$ spermatozoa $/ \mathrm{ml}$ for samples from the cauda epididymidis. Samples $(1 \mathrm{ml}) \mathrm{were}$ reactivated in transparent polystyrene dishes (Bunzl, Hendon, USA) by the addition of ATP (to make 1 mmol/l), examined with an inverted microscope (Zeiss, West Germany) at $32^{\circ} \mathrm{C}$, and scored according to the rate of progressive motility (scale 0-4) and percentage of motile spermatozoa (Jones et al., 1984).

\section{Incubation of spermatozoa in vitro}

The whole-droplet technique (Pholpramool et al., 1985) was used to incubate samples at $32^{\circ} \mathrm{C}$ under watersaturated paraffin oil on a cavitated glass microscope slide $(30 \mathrm{nl}$ of undiluted sample was deposited). The overall activity of the samples was scored on a scale of 0 -10: the response is referred to as scores of activity to distinguish it from scores of the rate of progressive motility of individual spermatozoa.

In one study, preparations of luminal plasma, separated from spermatozoa by centrifugation at $12000 \mathrm{~g}$ for $15 \mathrm{~min}$, were used to dilute micropuncture samples at 1:20. The effect of the concentration of extracellular calcium was examined in another experiment in which the calcium concentration was determined using a published estimate of spermatocrit (Jones, 1987) and concentration of calcium in plasma (Jones \& Clulow, 1987). In this study, micropuncture samples were diluted, or not diluted, to obtain estimated calcium concentrations of: 0 (1:20 dilution with Krebs-Ringer phosphate containing $4 \mathrm{mmol}$ EGTA/l), $12 \mu \mathrm{mol} / 1$ (1:20 dilution with Krebs-Ringer phosphate), $0.6 \mathrm{mmol} / 1$ (undiluted samples) and $2.5 \mathrm{mmol} / 1$ ( $1: 20$ dilution in Hepes buffer). In another experiment, the effect of extracellular $\mathrm{pH}$ was examined using Mes (pH 5.5) and Hepes (pH 7.4) buffers in diluents containing a permeant (20 mmol lactate $/ \mathrm{l})$ and impermeant $(20 \mathrm{mmol}$ glutamate/l) acid (Acott \& Carr, 1984). For one treatment, micropuncture samples $(30 \mathrm{nl})$ were initially diluted at 1:20 with the Mes buffer, then after $1 \mathrm{~h}$ the samples were diluted a second time (1:4) with the Hepes buffer to change the $\mathrm{pH}$ of the medium.

\section{Composition of buffers}

The Krebs-Ringer phosphate ( $\mathrm{pH} 6.8,290 \mathrm{mosmol} / \mathrm{kg}$ ) described by Umbreit et al. (1972) was used. The Hepes buffer $(295 \mathrm{mosmol} / \mathrm{kg}$ ) contained $40 \mathrm{mmol}$ Hepes $/ 1,123 \mathrm{mmol}$ sodium chloride $/ 1,2 \cdot 5 \mathrm{mmol}$ calcium chloride $/ 1$ and 
$1.2 \mathrm{mmol}$ magnesium sulphate/l and was adjusted to $\mathrm{pH} 7.4$ with potassium hydroxide. The composition of the Mes buffer ( $290 \mathrm{mosmol} / \mathrm{kg}$ ) was the same as the Hepes buffer except that it contained $46 \mathrm{mmol} \mathrm{Mes} \mathrm{and} 119 \mathrm{mmol}$ sodium chloride $/ 1$ and it was adjusted to $\mathrm{pH} 5.5$ with hydrochloric acid. The sodium-free buffers were prepared by replacing sodium chloride with choline chloride. When required by the design of the experiment, amiloride (a gift from Merck, Sharpe and Dohme, Granville, NSW) was added at $1 \mathrm{mmol} / 1$; glutamic and lactic acids were added at $20 \mathrm{mmol} / 1$ and EGTA was added to make a final concentration of $4 \mathrm{mmol} / 1$. All diluents contained $10 \mathrm{mmol}$ glucose/l; all the chemicals used were analytical reagent grade.

\section{Assays}

Lactate concentrations in blood and epididymal plasma were measured using an enzymatic assay (Bergmeyer, 1974). The viscoelasticity of epididymal plasma was measured as the rate of descent of a steel ball (diameter $765 \mu \mathrm{m})$ through a vertically orientated, glass column $(926 \mu \mathrm{m}$ internal diameter) filled with the test fluid (Usselman \& Cone, 1983).

\section{Statistical analysis}

Analyses of variance were carried out using the General Linear Models procedure of the SAS statistics programme (SAS Institute Inc., 1982). The unit of response in the analysis of variance is indicated in the Results where appropriate either as an index computed from the sum of scores made at intervals during a period of incubation (Emmens, 1947), or as the score at a specific time when the activity of samples at one time, or different times, were compared (Jones \& Martin, 1965). Error values are standard errors of the mean calculated from the variance between animals, or are indicated in the Results as being calculated from the pooled estimate of error in the analysis of variance.

\section{Results}

\section{Reactivation of demembranated spermatozoa}

Spermatozoa from the rete testis and cauda epididymidis were reactivated by ATP, but the percentage of motile spermatozoa was lower for samples from the rete testis than from the cauda epididymidis $(P<0.05 ;$ Fig. 1). The vigour of flagellar beating was correlated positively and closely with the percentage of motile spermatozoa (scores of this response are therefore not shown), and spermatozoa from the rete testis showed no forward progression whilst spermatozoa from the cauda epididymidis did (although the forward progression was hampered by the agglutination of many spermatozoa after the addition of ATP).

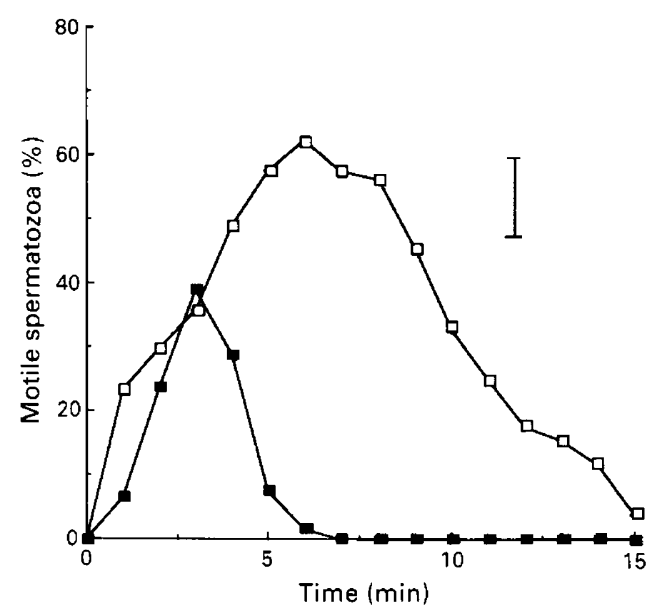

Fig. 1. Reactivation of demembranated spermatozoa from the rete testis ( $\boldsymbol{\square}$ ) and cauda epididymidis $(\square)$ after $1 \mathrm{mmol}$ ATP/l was added at time 0 to samples of spermatozoa demembranated with $0 \cdot 1 \%$ Triton X-100. Means from five tammars; error bar indicates the magnitude of the pooled standard error from the analysis of variance. 


\section{Activity of undiluted micropuncture samples}

Spermatozoa from the rete testis and all regions of the epididymis were immotile as they entered the micropuncture pipette during collection, which used little suction. However, samples became motile within the collection pipette or during subsequent incubation. There was an overall increase in the amount of activity developed by samples taken from successive sites along the genital ducts $(P<0.00$ l for analyses of indices calculated as the sum of individual scores over the 10-h period of incubation), but only weak activity in the proximal samples (Fig. 2). Samples from the mid-corpus were fully active $2 \mathrm{~h}$ earlier than samples from the cauda epididymidis, but high activity was sustained longer in the samples from the cauda epididymidis $(P<0.05$ for mean scores at $6 \mathrm{vs} .1 \mathrm{~h})$.

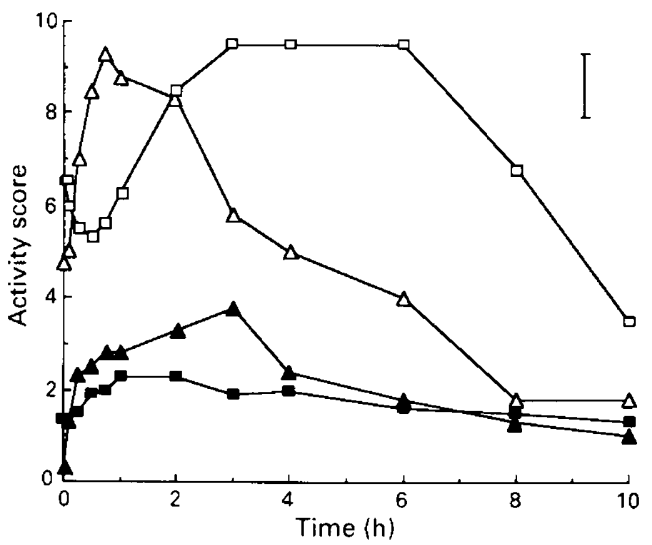

Fig. 2. Mean scores of activity (1 low, 10 high) of spermatozoa in undiluted micropuncture samples collected from the rete testis $(\boldsymbol{\square})$ and caput $(\boldsymbol{\Delta})$, mid-corpus $(\triangle)$ and distal cauda $(\square)$ epididymides and incubated at $32^{\circ} \mathrm{C}$ for $10 \mathrm{~h}$. Means from four tammars; error bar indicates the magnitude of the pooled standard error from the analysis of variance.

The suppression of sperm motility was examined further in micropuncture samples from the cauda epididymidis of an additional six tammars. For the ten animals examined, the mean time taken to achieve maximum activity was $1 \cdot 3 \pm 0.4 \mathrm{~h}$ (Fig. 3a), but there was considerable variation between samples. Three patterns of activity were observed in micropuncture samples dispensed under oil (Fig. 3b): (i) initially high activity which continued for 8-10 h (three animals); (ii) initially low activity which declined and then recovered (four animals); and (iii) initially zero activity, then high activity which developed and continued for at least $8 \mathrm{~h}$ (three animals).

\section{Role of native luminal fluids}

There was no effect of dilution on the survival of spermatozoa for $12 \mathrm{~h}$ at $32^{\circ} \mathrm{C}$ when micropuncture samples from the rete testis, distal caput epididymidis and cauda epididymidis were incubated undiluted or diluted 20 -fold in epididymal plasma from the cauda epididymidis. There was no effect of dilution of samples from the cauda epididymidis in luminal plasma from the rete testis.

\section{Effects of extracellular calcium on spermatozoa from the cauda epididymidis}

The activity of spermatozoa incubated in vitro for $8 \mathrm{~h}$ was dependent on the availability of extracellular calcium $(P<0.001$ for analyses of indices calculated as the sum of individual scores over the $8 \mathrm{~h}$ of incubation; Fig. 4). The activity of samples fell below a mean score of $5.0 \mathrm{in} 2 \mathrm{~h}$ with no calcium, $5 \mathrm{~h}$ with $12 \mu \mathrm{mol} \mathrm{Ca} / 1,6.5 \mathrm{~h}$ with $0.6 \mathrm{mmol} \mathrm{Ca} / 1$ and $>8 \mathrm{~h}$ for $2.5 \mathrm{mmol} \mathrm{Ca} / 1$. 


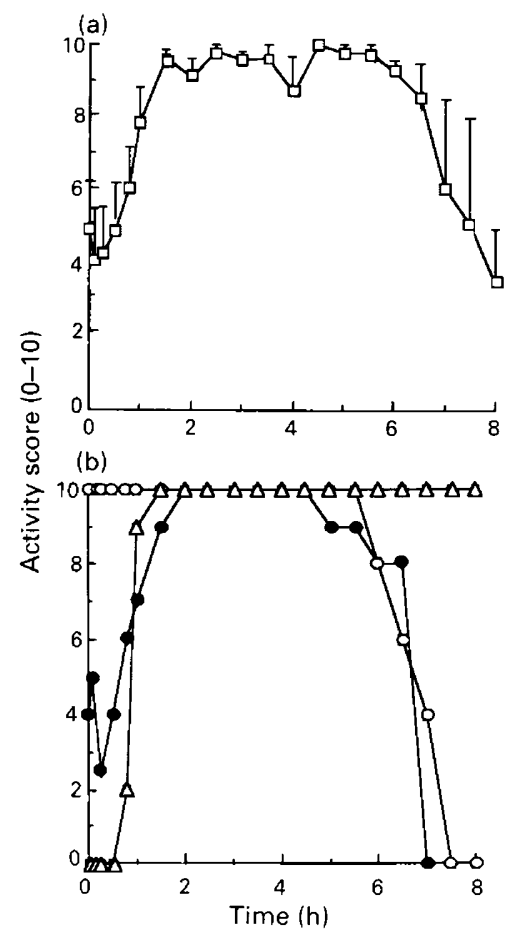

Fig. 3. Mean scores of activity ( 1 low, 10 high) of spermatozoa in undiluted micropuncture samples collected from the cauda epididymidis showing the pattern of initiation of motility during incubation in vitro at $32^{\circ} \mathrm{C}$ : (a) means \pm SEM from ten tammars; (b) patterns of motility initiation for three of the ten tammars, nos $11(\bigcirc), 15(\triangle)$ and $16(\bigcirc)$.

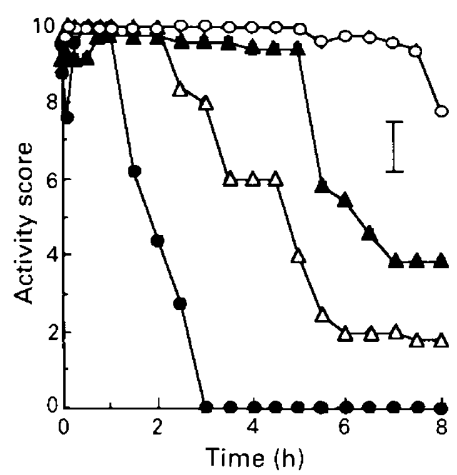

Fig. 4. Effects of $0 \mathrm{mmol}(\bullet), 12 \mu \mathrm{mol}(\triangle), 0.6 \mathrm{mmol}(\Delta)$ or $2.5 \mathrm{mmol}(\bigcirc)$ extracellular calcium/1 on the activity ( 1 low, 10 high) of spermatozoa from the cauda epididymidis during incubation at $32^{\circ} \mathrm{C}$. Means from four tammars; error bar indicates the magnitude of the pooled standard error from the analysis of variance.

\section{Effects of intracellular and extracellular pH on spermatozoa from the cauda epididymidis}

There was no effect of extracellular $\mathrm{pH}$ on spermatozoa diluted in acidic (pH 5.5) and/or alkaline ( $\mathrm{pH} 7$ 4) buffer containing impermeant acid (glutamate; Fig. 5). However, a low pH in the presence of the permeant acid (lactate) caused a decline in activity of spermatozoa $(P<0.001)$ to a 
mean score of $0 \cdot 7 \pm 0 \cdot 2$ after $1 \mathrm{~h}$. The response was immediately reversed by adjusting the medium to $\mathrm{pH} 7.0$ by a $1: 4$ dilution of the diluent with Hepes buffer.

\section{Effects of extracellular sodium on spermatozoa from the cauda epididymidis}

The activity of spermatozoa was not dependent on the concentration of extracellular sodium $>1 \mathrm{mmol} / \mathrm{l}$, and a $\mathrm{Na}^{+}-\mathrm{H}^{+}$exchange system was not involved in the maintenance of motility, because (i) motility in the absence of sodium was unaffected even at low extracellular $\mathrm{pH}$ and (ii) amiloride failed to inhibit motility (Table 1).

\section{Lactate and viscosity}

Mean lactate concentrations were lower in fluids from the rete testis $(1.58 \pm 0.37 \mathrm{mmol} / \mathrm{l})$ and cauda epididymidis $(2.72 \pm 0.53 \mathrm{mmol} / \mathrm{l})$ than in blood plasma $(3.93 \pm 0.05 \mathrm{mmol} / \mathrm{l} ; P<0.01$; means \pm SEM from five tammars).

It was much easier to draw luminal fluid from the cauda epididymidis of tammars than from that of rats ( $R$. C. Jones, unpublished data). Measurements of the relative viscosity of plasma from the cauda epididymidis of tammars were only slightly higher (inverse of rate of fall of steel ball was $1.06 \pm 0.26 \mathrm{~s} / 3 \mathrm{~cm}$; mean \pm SEM from four tammars) than the value obtained for water $(<1 \mathrm{~s} / 3 \mathrm{~cm})$ and much lower than the value for glycerol $(130.6 \pm 3.2 \mathrm{~s} / 3 \mathrm{~cm}$; mean $\pm \mathrm{sEM}$ from six readings).

\section{Discussion}

\section{Maturation of spermatozoa in the epididymis}

The results obtained in this study using undiluted micropuncture samples(Fig. 2) confirm an earlier finding using diluted samples from minced duct (Jones et al., 1984) that spermatozoa develop their maximum capacity for normal motility in the caput and corpus epididymidis in tammars. The persistence of strong motility in vitro for several hours longer in samples from the cauda than in samples from the mid-corpus epididymidis indicates that a part of the maturation process continues after spermatozoa appear to develop their full capacity for motility.

The reactivation of demembranated spermatozoa from the rete testis by the addition of ATP (Fig. 1) demonstrates that testicular spermatozoa from tammars are capable of vigorous flagellar beating, so that, as in the eutheria that have been studied (Mohri \& Yanagamachi, 1980; Yeung, 1984; White \& Voglmayr, 1986), sperm maturation in the epididymis of tammars must involve changes to the membranes. However, as spermatozoa from the rete testis of tammars do not develop a pattern of motility involving forward progression as in spermatozoa from the cauda epididymidis, more is clearly involved in epididymal maturation of spermatozoa in this marsupial than in the eutherians that have been studied.

\section{Sperm quiescence and spontaneous activation}

This is the first report to document the collection of immotile spermatozoa from the mammalian epididymis which then spontaneously become activated in vitro. Accordingly, motility may be suppressed in situ in tammars as spermatozoa develop the capacity for motility. However, the quiescence is highly sensitive to perturbation, and collection by micropuncture was sufficient to initiate motility of some samples even though any contamination with non-luminal fluids would, at the most, be limited to the first $100 \mathrm{nl}$ collected. The suppression of spermatozoa is thought to depend on a physiological mechanism in situ, since all the undiluted samples that were studied eventually became highly motile during incubation in vitro (Figs 2 and 3), and dilution of the 


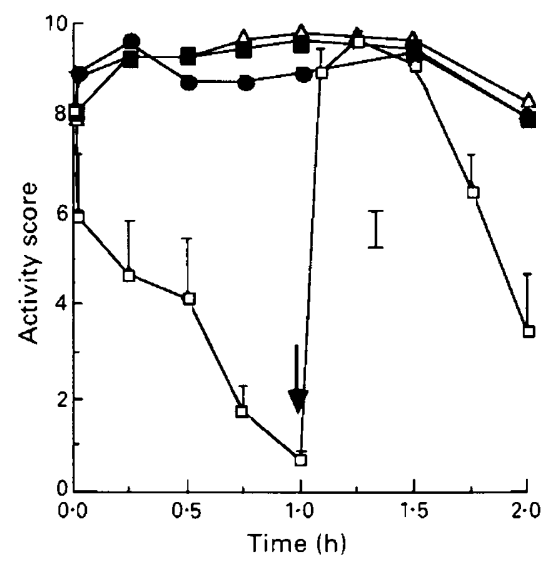

Fig. 5. Effects of $\mathrm{pH}$ on the activity score (1 low, 10 high) of spermatozoa from the cauda epididymidis during incubation at $32^{\circ} \mathrm{C}$. Arrow indicates when spermatozoa at $\mathrm{pH} 5.5$ were diluted 1:4 with Hepes buffer to raise the $\mathrm{pH}$ of the medium; $(\triangle) \mathrm{pH} 5.5$, ( $) \mathrm{pH} 5.5$ and glutamate diluent, $(\square) \mathrm{pH} 5.5$ and lactate diluent, $(\odot) \mathrm{pH} \mathrm{7.4}$. Means from four tammars; error bar indicates the magnitude of the pooled standard error from the analysis of variance.

Table 1. Mean scores of activity of spermatozoa from the cauda epididymidis of the tammar incubated for $1 \mathrm{~min}$ or $2 \mathrm{~h}$ at $32^{\circ} \mathrm{C}$ either undiluted or after dilution at 1:20 with Hepes (pH 7.4) or Mes (pH 5.5) buffer containing different concentrations of sodium and 0 or $1 \mathrm{mmol}$ amiloride/l

\begin{tabular}{lcccc}
\hline \multirow{2}{*}{ Composition of diluent } & & \multicolumn{3}{c}{ Activity after: } \\
& $\mathrm{pH}$ & $n^{*}$ & $1 \mathrm{~min}$ & $2 \mathrm{~h}$ \\
\hline Samples undiluted & $6 \cdot 3^{\mathrm{b}}$ & 8 & $2 \cdot 0 \pm 1 \cdot 0$ & $9 \cdot 0 \pm 0 \cdot 4$ \\
$115 \mathrm{mmol} \mathrm{Na} / \mathrm{l}$ & $7 \cdot 4$ & 8 & $7 \cdot 1 \pm 0 \cdot 8$ & $8 \cdot 3 \pm 0 \cdot 8$ \\
$115 \mathrm{mmol} \mathrm{Na} / \mathrm{l} 1 \mathrm{mmol}$ amiloride $/ 1$ & $7 \cdot 4$ & 5 & $9 \cdot 2 \pm 0 \cdot 4$ & $7 \cdot 6 \pm 1 \cdot 7$ \\
$1 \mathrm{mmol} \mathrm{Na} / \mathrm{l}^{*}$ & $7 \cdot 4$ & 5 & $9 \cdot 0 \pm 0 \cdot 3$ & $7 \cdot 6 \pm 1 \cdot 7$ \\
$1 \mathrm{mmol} \mathrm{Na} / \mathrm{l}^{\mathrm{a}}$ & $5 \cdot 5$ & 3 & $7 \cdot 3 \pm 0 \cdot 3$ & $9 \cdot 7 \pm 0 \cdot 3$ \\
$P($ mean 1 vs. mean 2-4) & & & & $\mathrm{NS}$ \\
\hline
\end{tabular}

"Diluents prepared using choline chloride instead of sodium chloride; data from Jones \& Clulow (1987) were used to calculate the final concentration of sodium after the $1: 20$ dilution of semen.

'From Jones \& Cluiow (1987).

* Number of tammars sampled.

$* * * P<0.001$.

samples in native epididymal fluid had no suppressive effect. The nature of the suppressive mechanism is not understood.

The demonstration in this study of the tenuous nature of the quiescence of spermatozoa in the epididymis of tammars questions the interpretation of studies on other mammals, which found high motility of undiluted samples from the epididymis (see Introduction).

\section{Regulation of sperm motility in vitro and in situ}

The experiments reported in this study clearly demonstrate that including lactate in a diluent of low $\mathrm{pH}$ reversibly suppresses the motility of tammar spermatozoa. In this respect, the tammar closely follows the bovine model (Acott \& Carr, 1984; Carr \& Acott, 1984, 1989) in which the 
reversible loss of motility after the addition of lactate is associated with a reduction in intracellular $\mathrm{pH}$. Alterations to intracellular $\mathrm{pH}$ may, therefore, provide a mechanism for the regulation of metabolism and motility in both eutherian and metatherian spermatozoa. However, even though the extracellular $\mathrm{pH}$ is acidic (pH 6.3; Jones \& Clulow, 1987), the lactate concentrations are low in fluid from the cauda epididymidis of tammars, so that it is unlikely that lactate alone is the regulating factor in situ.

That tammar spermatozoa do not require extracellular sodium to maintain motility indicates that they differ from rat spermatozoa, which require $>50 \mathrm{mmol}$ extracellular sodium/l to maintain vigorous motility and can be inactivated by amiloride (Wong et al., 1981). The absence of a combined effect of extracellular protons and sodium indicates that the $\mathrm{Na}^{+}-\mathrm{H}^{+}$exchange system is probably not important for maintaining intracellular $\mathrm{pH}$ in tammars, as it is in the rat. The low viscosity of its epididymal fluid also differentiates tammars from rats; sperm motility in situ is inhibited by the high viscosity of epididymal fluid (Usselman \& Cone, 1983; Carr et al., 1985; Turner \& Reich, 1985). It would be interesting to determine whether bovine spermatozoa, which have a similar $\mathrm{pH} /$ lactate response to tammar spermatozoa, are also independent of extracellular sodium for the regulation of intracellular $\mathrm{pH}$.

Extracellular calcium limits the survival of spermatozoa from tammars during incubation in vitro and its effect is dependent on concentration (Fig. 4). Studies in vitro of the effects of extracellular calcium on eutherian spermatozoa have produced differing results, even for the same species (Tash \& Means, 1983; Bradley \& Forrester, 1985). Much of this confusion may be due to a failure to take into account the proportion of extracellular calcium that is physiologically available in an ionized form (Tash \& Means, 1983; Bradley \& Forrester, 1985).

We are grateful for technical help from G. Chaturapanich and L. A. Hansen. The work was supported by a grant from the Australian Research Council.

\section{References}

Acott, T.S. \& Carr, D.W. (1984) Inhibition of bovine spermatozoa by caudal epididymal fluid. II. Interaction of $\mathrm{pH}$ and a quiescence factor. Biol. Reprod. 30, 926-935.

Babcock, D.F., Rufo, G.A. \& Lardy, H.A. (1983) Potassium-dependent increases in cytosolic $\mathrm{pH}$ stimulate metabolism and motility of mammalian sperm. Proc. Natl Acad. Sci. 80, 1327-1331.

Bergmeyer, H.U. (1974) Methods of Enzymatic Analysis, Vol. 3, pp. 1465-1472. Academic Press, NY.

Bradley, M.P. \& Forrester, I.T. (1985) Sperm calcium homeostasis during maturation. In Male Fertility and its Regulation, pp. 437-449. Eds T. Lobl \& E. S. E. Hafez. MTP Press, Hingham, USA.

Carr, D.W. \& Acott, T.S. (1984) Inhibition of bovine spermatozoa by caudal epididymal fluid. I. Studies of a sperm motility quiescence factor. Biol. Reprod. 30, 913-925.

Carr, D.W. \& Acott, T.S. (1989) Intracellular pH regulates bovine sperm motility and protein phosphorylation. Biol. Reprod. 41, 907-920.

Carr, D.W., Usselman, M.C. \& Acott, T.S. (1985) Effects of $\mathrm{pH}$, lactate, and viscoelastic drag on sperm motility: a species comparison. Biol. Reprod. 33, 588-595.

Cascieri, M., Amman, R.P. \& Hammerstedt, R.H. (1976) Adenine nucleotide changes at initiation of bull sperm motility. J. Biol. Chem. 251, 787-793.

Djakiew, D. \& Jones, R.C. (1983) Sperm maturation, fluid transport and secretion and absorption of protein from the epididymis of the echidna, Tachyglossus aculeatus. J. Reprod. Fert. 68, $445 * 456$.

Emmens, C.W. (1947) The motility and viability of rabbit spermatozoa at different hydrogen ion concentrations. J. Physiol. 106, 47 I-481.

Garbers, D.L. \& Kopf, G.S. (1980) The regulation of spermatozoa by calcium and cyclic nucleotides. $A d v$. Cyclic Nucleotide Res. 13, 251-307.

Harding, H.R., Carrick, F.N. \& Shorey, C.D. (1975) Ultrastructural changes in spermatozoa of the brushtailed possum, Trichosurus vulpecula (Marsupialia), during epididymal transit. Part 1: The flagellum. Cell Tiss. Res. 164, 121-132.

Harding, H.R., Carrick, F.N. \& Shorey, C.D. (1979) Special features of sperm structure and function in marsupials. In The Spermatozoon Maturation, Motility, Surface Properties and Comparative Aspects, pp. 289-303. Eds D. W. Fawcett \& J. M. Bedford. Urban \& Schwarzenberg, Baltimore, MD.

Jones, R. (1978) Comparative biochemistry of mammalian epididymal plasma. Comp. Biochem. Physiol. 61B, $365-370$.

Jones, R.C. (1973) Collection, motility and storage of spermatozoa from the African elephant, Loxodonta africana. Nature, Lond. 243, 38-39.

Jones, R.C. (1978) Studies on handling spermatozoa from the African elephant. Symp. zool. Soc. Lond. 43, $261-269$. 
Jones, R.C. (1987) Changes in protein composition of the luminal fluids along the epididymis of the tammar, Macropus eugenii. J. Reprod. Fert. 80, 193-199.

Jones, R.C. (1989) Reproduction in male Macropodidae. In Kangaroos, Wallabies and Rat-kangaroos, pp. 287-305. Eds G. Grigg, P. Jarman \& I. Hume. Surrey, Beatty and Sons, NSW, Australia.

Jones, R.C. \& Clulow, J. (1987) Regulation of the epididymal composition of the epididymal fluids of the tammar, Macropus eugenii. J. Reprod. Fert. 81, $583-590$.

Jones, R.C. \& Martin, I.C.A. (1965) Deep-freezing ram spermatozoa: the effects of milk, yolk-citrate and synthetic diluents containing sugar. J. Reprod. Fert. 10, 413. 423 .

Jones, R.C., Hinds, L.A. \& Tyndale-Biscoe, C.H. (1984) Ultrastructure of the epididymis of the tammar, Macropus eugenii, and its relationship to sperm maturation. Cell Tiss. Res. 237, 525-535.

Lee, W.M., Tsang, A.Y.F. \& Wong, P.Y.D. (1981) Effects of divalent and lanthanide ions on motility initiation in rat caudal epididymal spermatozoa. $\mathrm{Br}$. J. Pharmac. 73, 633-638.

Lindemann, C.B. \& Kanous, K.S. (1989) Regulation of mammalian sperm motility. Arch. Androl. 23, 1-22.

Mohri, H. \& Yanagamachi, R. (1980) Characteristics of motor apparatus in testicular, epididymal and ejaculated spermatozoa. Exp. Cell Res. 127, 191-196.

Morton, B.E., Sagadraga, R. \& Fraser, C. (1978) Sperm motility within the mammalian epididymis; species variation and correlation with free calcium levels in epididymal plasma. Fert. Steril. 29, 695-698.

Pholpramool, C., Zupp, J.L. \& Setchell, B.P. (1985) Motility of undiluted bull epididymal spermatozoa collected by micropuncture. J. Reprod. Fert. 75, $413-420$.
SAS Institute Inc. (1982) SAS User's Guide: Statistics. SAS Institute Inc., Cary, NC, USA.

Tash, J.S. \& Means, A.R. (1983) Cyclic adenosine 3',5'monophosphate, calcium and protein phosphorylation in flagellar motility. Biol. Reprod. 28, 75-104.

Turner, T.T. \& Reich, G.W. (1985) Cauda epididymal sperm motility: a comparison among five species. Biol. Reprod. 32, 120-I28.

Umbreit, W.W., Burris, R.H. \& Stauffer, J.F. (1972) Manometric and Biochemical Techniques, 5th edn, p. 146. Burgess Pub Co., Minneapolis.

Usselman, M.C. \& Cone, R.A. (1983) Rat sperm are mechanically immobilized in the caudal epididymis by 'immobilin', a high molecular weight glycoprotein. Biol. Reprod. 29, $1241 \cdots 1253$.

Vijayaraghavan, S., Critchlow, L.M. \& Hoskins, D.D. (1985) Evidence for a role for cellular alkalinization in the cyclic adenosine $3^{\prime}, 5^{\prime}$-monophosphate-mediated initiation of motility in bovine caput spermatozoa. Biol. Reprod. 32, 489-500.

White, I.G. \& Voglmayr, J.K. (1986) ATP-induced reactivation of ram testicular, cauda epididymal, and ejaculated spermatozoa extracted with Triton X-100. Biol. Reprod. 34, 183-193.

Wong, P.Y.D. \& Lee, W.M. (1985) Ionic mechanisms of sperm motility initiation. In Male Fertility and its Regulation, pp. 411-416. Eds T. Lobl \& E. S. E. Hafez. MTP Press, Hingham, USA.

Wong, P.Y.D., Lee, W.M. \& Tsang, A.Y.F. (1981) The effects of extracellular sodium on acid release and motility initiation in rat caudal epididymal spermatozoa in vitro. Exptl Cell Res. 131, 97-104.

Yeung, C.H. (1984) Effects of cyclic AMP on the motility of mature and immature hamster epididymal spermatozoa studied by reactivation of demembranated cells. Gamete Res. 9, 99-114.

Received 24 October 1990 